\title{
Avaliação da Produção de Lacase por Ganodermalucidum UEM na Presença de I ndutores
}

\author{
Bruna Polacchine da Silva ${ }^{1}$, Caroline Aparecida Vaz de Araujo, Tatiane Brugnari', \\ Elidiane Andressa Rodrigues ${ }^{1}$, Miguel Leal Neto' ${ }^{1}$, Rosane Marina Peralta ${ }^{1}$ \\ ${ }^{1}$ Universidade Estadual de Maringá - Departamento de Bioquímica \\ CEP87020-900 - Maringá- PR - E-mail: (brunapol@hotmail.com)
}

\begin{abstract}
RESUMO
Lacase é uma fenoloxidase produzida por fungos ligninolíticos com aplicações em biorremediação e pré-tratamento de fibras lignocelulósicas. Sua produção pode ser estimulada por indutores no cultivo. Nosso objetivo foi avaliar o efeito de indutores na produção de lacase por Ganodermalucidum. O fungo foi cultivado em meio contendo glicose e nitrato de amônia suplementado ou não cometanol 3\% (v/v), ácido gálico ( $1 \mathrm{mM}), \mathrm{CuSO}_{4}$ $(0,4 \mathrm{mM})$, e suas combinações: etanol $3 \%(\mathrm{v} / \mathrm{v})$ + ácido gálico $(1 \mathrm{mM})$; etanol $3 \%(\mathrm{v} / \mathrm{v})+$ $\mathrm{CuSO}_{4}(0,4 \mathrm{mM})$; ácido gálico $(1 \mathrm{mM})+\mathrm{CuSO}_{4}(0,4 \mathrm{mM})$; etanol $3 \%(\mathrm{v} / \mathrm{v})+$ ácido gálico $(1 \mathrm{mM})$ + $\mathrm{CuSO}_{4}(0,4 \mathrm{mM})$, a 280 $\mathrm{C}$, sob agitação por $144 \mathrm{~h}$. Obteve-se máximo de lacases em indutor $\left(67,15 \pm 37,51\right.$ U. $\left.L^{-1}\right)$ após 96 , já com etanol a 3\%, foi de583,12 $\pm 140,7$ U. L $^{-1}$ após 144h. Este resultado sugere potencial uso de etanol a 3\% como indutor da produção de lacase por Ganodermalucidum.
\end{abstract}

Palavras-chave: Ganodermalucidum, lacase, indutores enzimáticos.

\section{NTRODUÇÃO}

A lacase (benzenodiol: oxigênio oxidorredutase, EC 1.10.3.2.) é uma polifenol oxidase que contêm cobre na sua estrutura e catalisa a oxidação de uma série de substâncias inorgânicas e aromáticas (particularmente fenóis) com a concomitante redução do oxigênio a água. Estas enzimas atuam pela abstração de um elétron de fenóis, em função da redução de $\mathrm{Cu}^{2+}$ a $\mathrm{Cu}^{1+}$ que, por sua vez, reduz $\mathrm{O}_{2}$ a $\mathrm{H}_{2} \mathrm{O}$, permitindo que a enzima atue de forma cíclica (BORTOLAZZO et al., 2011; AGUIAR\& FERRAZ, 2011). Devido à sua capacidade de degradar compostos fenólicos, a lacase pode ser aplicada em diversas áreas da indústria, tais como,descoloração de corantes têxteis, desintoxicação de águas residuais, degradação de pesticidas e herbicidas e hidrocarbonetos policíclicos aromáticos (WIDSTEN\& KANDELBAUER, 2008).

O fungo Ganodermalucidum (Fr.) Krasté um basidiomiceto pertencente à família Ganodermataceae,conhecido por produzir elevadas quantidades de lacase em cultivos submersos e em estado estacionário.A produção e atividade da lacase é influenciada pela linhagem, composição do substrato e condições de cultivo do fungo (ELISASHIVILlet al., 2008), além do tipo e concentração de indutores presentes no cultivo. Já se sabe que no gênero Ganoderma, pirogalol e ácido ferúlico são potentes indutores (ELISASHIVILlet al., 2010), assim como o ácido gálico, xilidina, vanilina, alcoóis e CuSO ${ }_{4}$ (MANAVALAN et al., 2013). Assim, considerando o grande potencial biotecnológico e elevado potencial de mercado da lacase, este trabalho busca estabelecer o melhor indutor para a produção desta enzima pelo fungo Ganodermalucidumem cultivos submersos.

Universidade Estadual de Londrina - Rodovia Celso Garcia Cid, Pr 445, Km 380 - Campus Universitário Caixa Postal 10.011 CEP 86057-970 Centro de Ciências Exatas - Departamento de Bioquímica e Biotecnologia Fone +55 (43) 3371.4270 - biq@uel.br 


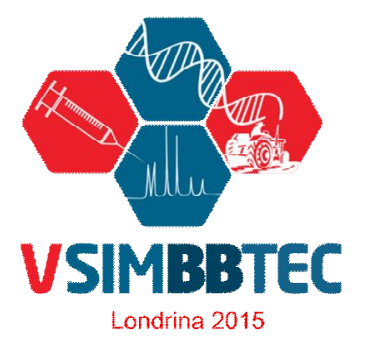

\section{SIMPÓSIO DE BIOQUÍMICA E BIOTECNOLOGIA}

05 a 07 de agosto de 2015, Londrina - PR

\section{MATERI AL E MÉTODOS}

Microrganismo e manutenção: O fungo Ganodermalucidum UEM, pertence à Coleção de Basidiomicetos do Laboratório de Bioquímica de Microrganismos da Universidade de Estadual de Maringá é mantido através de repiques periódicos em ágar-batata-dextrose.

Condições de cultivo com os indutores: Os cultivos submersos foram conduzidos em frascos Erlenmeyers de $125 \mathrm{~mL}$, com $25 \mathrm{~mL}$ de meio basal $\left(10 \mathrm{~g} \cdot \mathrm{L}^{-1}\right.$ de glicose e $2 \mathrm{~g} . \mathrm{L}^{-1}$ de nitrato de amônio mais solução mineral de Vogel(meio basal ou controle). Após autoclavação, os seguintes indutoresforam adicionados sob condições estéreis: etanol $3 \%$ $(\mathrm{v} / \mathrm{v})$, ácido gálico $(1 \mathrm{mM})$ e $\mathrm{CuSO}_{4}(0,4 \mathrm{mM})$, e suas combinações: etanol $3 \%(\mathrm{v} / \mathrm{v})+$ ácido gálico (1mM); etanol $3 \%(\mathrm{v} / \mathrm{v})+\mathrm{CuSO}_{4}(0,4 \mathrm{mM})$; ácido gálico $(1 \mathrm{mM})+\mathrm{CuSO}_{4}(0,4 \mathrm{mM})$; e etanol $3 \%(\mathrm{v} / \mathrm{v})+$ ácido gálico $(1 \mathrm{mM})+\mathrm{CuSO}_{4}(0,4 \mathrm{mM})$. Três discos de micélio obtidos de placas de BDA foram utilizados como inóculo. Os frascos foram mantidos sob agitação de 120 rpmà $28^{\circ} \mathrm{C}$, por 6 dias, sendo alíquotas de $500 \mu$ r retiradas a cada $24 \mathrm{~h}$ para determinação da atividade lacase.

Dosagem da lacase:A atividade da lacase foi mensurada com 2,2'-azino-bis (3etilbenzotiazolina-6-sulfônico) (ABTS) em $50 \mathrm{mM}$ de tampão acetato de sódio pH4.0, sendo a oxidação do ABTS determinada pelo aumento da absorbância a $420 \mathrm{~nm}\left(\varepsilon=36 \mathrm{mM}^{-1} \mathrm{~cm}^{-1}\right)$. A atividade enzimática foi determinada a $40^{\circ} \mathrm{C}$ e expressa em unidade enzimática internacional $\left(\mathrm{U}=\mu \mathrm{mol} \times 10 \mathrm{~min}^{-1}\right)$.

Análise estatística: Os experimentos foram realizados em duplicata e os dados são expressos como média \pm desvio padrão. As diferenças estatisticamente significativas entre as médias foram determinadas utilizando two-way ANOVA $(p<0,01)$ utilizando o programa estatística GraphPrism 6.

\section{RESULTADOS E DISCUSSÃO}

A Figura 1 mostra a produção de lacase em função do tempo de cultivo nos meioscontrole e nos meios suplementados com diferentes indutores. Na ausência de indutor, máximo de lacase $\left(67,15 \pm 37,51 \mathrm{U}\right.$. $\left.^{-1}\right)$ foi obtido após $96 \mathrm{~h}$ de cultivo.Pode-se observar que dentre os indutores utilizados, os melhores resultados (em ordem decrescente) foram obtidos nos cultivos com etanol a $3 \%\left(583,12 \pm 140,7\right.$ U.L $\left.^{-1}\right)$ após 144 h de cultivo, $\mathrm{CuSO}_{4}(45,84 \pm 14,91$ U. $\mathrm{L}^{-1} \pm$ ) e ácido gálico $\left(44,64 \pm 0,98\right.$ U. $\left.\mathrm{L}^{-1}\right)$ após $48 \mathrm{~h}$ de cultivo.Este resultado pode ser justificado pelo efeito de alcoóis sobre a membrana fúngica, o que facilitaria a secreção desta enzima, além do estresse oxidativo provocado por este solvente, o que acarretaria uma indução da lacase (LEEet al., 1999).

Compostos fenólicos como ácido gálico e $\mathrm{CUSO}_{4}$ também são descritos como indutores de lacases para diferentes fungos ligninolíticos (SOUZAet al., 2004). Para G. lucidum, entretanto, não mostraram eficiência na indução de lacases. Quando se associou ácido gálico e $\mathrm{CuSO}_{4}$ ao etanol, os níveis de atividade lacase obtidos foram menores do que nos cultivossomente com etanol como indutor.

Não houve diferença significativa entre o controle e os cultivos suplementados com CuSO ${ }_{4} \mathrm{e}$ ácido gálico isoladamente, o que contraria os resultados obtidos por outros autores (MANAVALAN et al. 2013).Silva e colaboradores (2012) também obtiveram aumento significativo da produção de lacase por linhagens de Lentinulaedodes, Pleurotusostreatus e Pleurotus floridacom a adição de $\mathrm{CuSO}_{4}$ na concentração de $150 \mu \mathrm{M}$ feita após 3 dias de cultivo, e não no início do processo fermentativo como em nosso experimento.

Universidade Estadual de Londrina - Rodovia Celso Garcia Cid, Pr 445, Km 380 - Campus Universitário Caixa Postal 10.011 CEP 86057-970 Centro de Ciências Exatas - Departamento de Bioquímica e Biotecnologia Fone +55 (43) 3371.4270 - biq@uel.br 


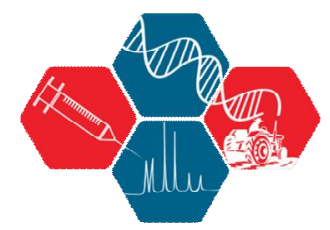

\section{VSIMBBTEC}

\section{SIMPÓSIO DE BIOQUÍMICA E BIOTECNOLOGIA}

\section{5 a 07 de agosto de 2015, Londrina - PR}

Londrina 2015

Comrelação ao tempo de cultivo, os resultados foram variados de acordo com o indutor ou combinação deste. Para o etanol a 3\%, após $72 \mathrm{~h}$ de cultivo houve um aumento significativo da produção de lacase, e este aumento seguiu exponencialmente, resultado observado também em suas combinações com ácido gálico $\mathrm{eCuSO}_{4}$, ou com ambos, resultados estes que corroboram com Silva et al. (2012), o qual obteve pico máximo de produção de lacase após 12 dias de cultivo deL.edodes, P.ostreatus e P.florida. Já para o ácido gálico $\mathrm{eCuSO}_{4} \mathrm{e} a$ combinação deste, até $72 \mathrm{~h}$ obtivemos produção de lacase similar ao controle, sendo esta inibida após este período.

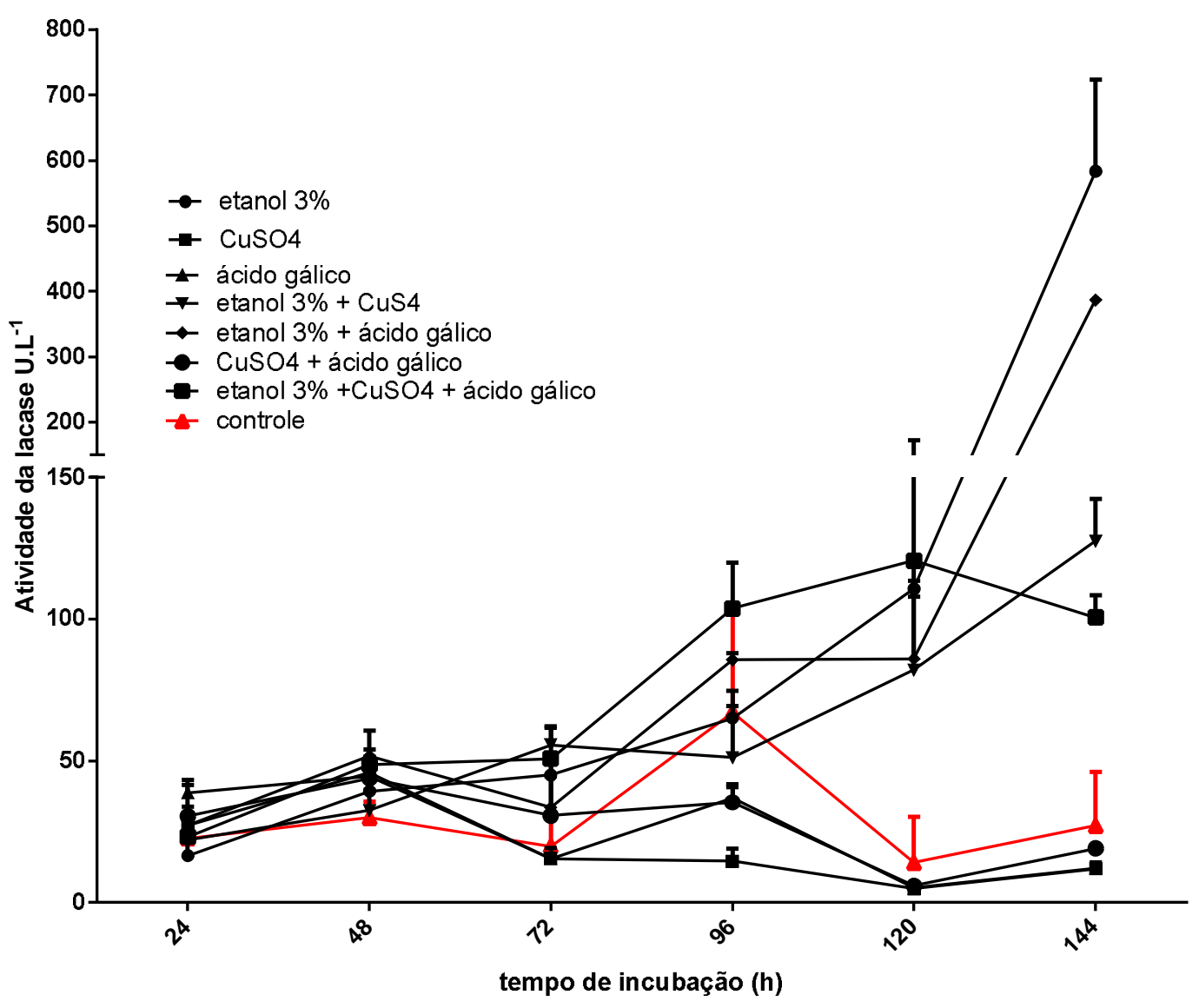

Figura 1: Atividade da lacase produzida por Ganodermalucidum UEM obtida em meio basal e na presença de diferentes indutores e suas combinações em cultivos submersos. As culturas foram desenvolvidas a 120 rpm e $28^{\circ}$ C.

\section{CONCLUSÕES}

Os resultados indicam que para aindução da produção de lacase, dentre os compostos analisados,a adição de etanol a 3\% foi a mais eficiente, sendo exponencial a partir de $72 \mathrm{~h}$ de cultivo, seguido de $\mathrm{CuSO}_{4} \mathrm{e}$ ácido gálico. Contudo, a associação dos indutores não teve um efeito aditivo de indução.

Agências de Fomento: Capes, CNPq.

Universidade Estadual de Londrina - Rodovia Celso Garcia Cid, Pr 445, Km 380 - Campus Universitário Caixa Postal 10.011 CEP 86057-970 Centro de Ciências Exatas - Departamento de Bioquímica e Biotecnologia Fone +55 (43) 3371.4270 - biq@uel.br 


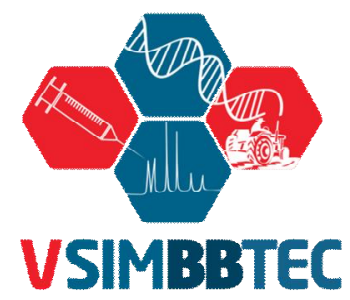

Londrina 2015

\section{REFERÊNCIAS}

Aguiar, A.; Ferraz, A. Mecanismos envolvidos na biodegradação de materiais lignocelulósicos e aplicações tecnológicas correlatas. Química Nova, v. 34, p. 1729-1738, 2011.

Bortolazzo, N. G. I solamento e seleção de fungos celulolíticos para hidrólise enzimática do bagaço-decana de açúcar. Dissertação (Mestrado em Ciências) - Escola Superior de Agricultura "Luiz de Queiroz", Universidade de São Paulo, Piracicaba, 2011.

Elisashvili, V.; Penninckx, M.; Kachlishvili, E.; Tsiklauri, N.; Metreveli, E.; Kharziani, T.; Kvesitadze, G. Lentinusedodesand Pleurotusspecies lignocellulolytic enzymes activity in submerged and solidstate fermentation of lignocellulosic wastes of different composition. Bioresource Technology, v. 99, p. 457-462, 2008.

Elisashvili, V.; Kachlishvili, E.; Kharziani, T.; Agathos, S.N. Effect of aromatic compounds on the production of lacase and manganese peroxidase by white-rot basidiomycetes, J ournal of Industrial Microbiology \&Biotechnology, p. 1091-1096, 2010.

Gao, D., Du, L., Yang, J., Wu, W.-M., Liang, H. A critical review of the application of white rot fungus to environmental pollution control.Critical Reviews in Biotechnology. V. 30, p.70-77, 2010.

Lee, I.Y.; ung, K.H.; Lee,C.H.; Park, Y.H. Enhanced production of lacase in Trametesversicolor by the addition of ethanol. Biotechnology Letters, v. 21, p. 965-968, 1999.

Manavalan, T.; Manavalan, A.; Thangavelu, K.P.; Heese, K. Characterization of optimized production, purification and application of lacase from Ganodermalucidum, Biochemical Engeneering J ournal, v. 70, p. 106-114, 20013.

Silva, J.J. da; Santana, T.T.; Oliveira, A. C.C; Almeida, P.H. de; Souza, S. G. H. de; Linde, G.A.; Colauto, N.B.; Valle, J. S. do. Produção de lacase de fungos basidiomicetos por fermentação submersa com casca de café. Arquivos de CiênciasVeterinárias eZoologia da UNIPAR, v. 15, n. 2, supl 1, p. 191-196, 2012.

Souza, C.G.M.; Tychanovicz, G.K.; Souza, D.F.; Peralta, R.M.Production of laccase isoforms by Pleurotus pulmonarius in response to presence of phenolic and aromatic compounds. Journal of BasicMicrobioliology, v. 44 , p. 129-136, 2004

Widsten, A.; Kandelbauer, A. Laccase applications in the forest products industry: a review. Enzyme and Microbial Technology, v. 42, p. 293-307, 2008.

Universidade Estadual de Londrina - Rodovia Celso Garcia Cid, Pr 445, Km 380 - Campus Universitário

Caixa Postal 10.011 CEP 86057-970 Centro de Ciências Exatas - Departamento de Bioquímica e

Biotecnologia Fone +55 (43) 3371.4270 - biq@uel.br 